\title{
A BAIXADA SANTISTA E OS DESAFIOS DO PLANEJAMENTO URBANO E REGIONAL \\ O FUTURO PASSA PELO PRÉ-SAL... OPORTUNIDADE E/OU AMEAÇA?
}

Mônica Antonia Viana ${ }^{1}$

\section{RESUMO}

Este artigo procura refletir sobre as expectativas futuras de desenvolvimento socioeconômico para a Região Metropolitana da Baixada Santista - RMBS, diante do novo papel dessa importante região portuária, industrial, turística e agora petrolífera para o desenvolvimento do estado e do país. Após a descoberta do Pré-sal, aposta-se na exploração e produção de petróleo e gás na Bacia de Santos, como potencial de desenvolvimento futuro da região para ampliar a produção e acumulação de riquezas. Sem dúvida uma grande oportunidade para promover o desenvolvimento regional, mas que também pode agravar os problemas existentes, criar novos e ampliar as desigualdades (riscos). Assim, apontar os desafios a serem enfrentados pelo planejamento urbano e regional para antever impactos e transformaçôes no território e para promover o desenvolvimento em bases sustentáveis.

Palavras-chave: Desenvolvimento sustentável; Planejamento urbano e regional; Baixada Santista; Petróleo e gás; Pré-sal Bacia de Santos.

Professora de Planejamento Urbano e Regional no curso de Arquitetura e Urbanismo da UniSantos e líder do grupo de pesquisa Observa BS da FAUS/UniSantos. Consultora e pesquisadora na área de Planejamento Urbano-Regional e Gestão Ambiental. e-mail: moviana@uol.com.br 
-• Economia Brasileira em Debate

\section{INTRODUÇÃO}

O Brasil e a Região Metropolitana da Baixada Santista - RMBS ${ }^{2}$ vivenciaram na última década uma nova fase de grande otimismo quanto às perspectivas futuras de desenvolvimento do país e da região, muito em função das descobertas das reservas de petróleo e gás na Bacia de Santos, nas áreas do chamado pré-sal. O que pode ser considerado uma realidade, tendo em vista que no período entre 2010 a 2014, a média anual de produção diária do pré-sal cresceu quase 12 vezes, avançando de uma média de 42 mil barris por dia em 2010 para 492 mil barris por dia em 2014. A produção chegou a mais de 800 mil barris por dia no pré-sal, apenas oito anos após a primeira descoberta na Bacia de Santos, ocorrida em 2006. Dez anos após, em meados de 2016, "a produção diária de petróleo no pré-sal passou para o patamar de 1 milhão de barris por dia, um crescimento de quase 24 vezes em relação a produção de 2010.” (PETROBRAS, 2017)

Segundo estudos do Observatório Litoral Sustentável do Instituto Polis (2016), a evolução do montante de recursos nos últimos 10 anos na RMBS foi significativa e existe uma perspectiva para os próximos anos de aumento desta receita em função das novas explorações previstas com o pré-sal, que ingressa na $3^{\text {a }}$ fase de licenciamento ambiental. Houve aumento expressivo do valor de recursos que a região recebeu no período de 2010 a 2014, oriundos dos royalties da exploração de petróleo e gás na Bacia de Santos, que passou de R \$ 41,5 milhões para R 128 milhões, conforme levantamento mais recente do Tribunal de Contas do Estado de São Paulo (apud POLIS, 2016). Todavia a grande questão é se esse montante que é distribuído entre os nove municípios da RMBS de acordo com a sua posição geográfica e a instalação dos empreendimentos da cadeia produtiva do petróleo e gás tem de fato contribuído para ampliar os investimentos em políticas públicas que possibilitem um desenvolvimento sustentável dos municípios e da região.

Neste contexto, este artigo procura refletir sobre as expectativas futuras de desenvolvimento socioeconômico para a RMBS, expressas na última década, diante do novo papel dessa importante região portuária, industrial, turística e agora

2 A RMBS criada em 1996 é composta por 9 municípios - Bertioga, Cubatão, Guarujá, Itanhaém, Mongaguá, Paria Grande, Peruíbe, Santos e São Vicente (AGEM-BS, 2016). 
petrolífera, que se torna ainda mais estratégica para o desenvolvimento da economia estadual, nacional e internacional. Vislumbra-se na exploração e produção de petróleo e gás na Bacia de Santos, como um potencial de desenvolvimento futuro da região, como forma de ampliar a produção e acumulação de riquezas. Sem dúvida, uma grande oportunidade que pode ser o motor do desenvolvimento regional, mas que também pode agravar os problemas existentes, criar novos e ampliar as desigualdades sociais (riscos/ameaças). (VIANA, 2010)

Cabe destacar que o risco está associado a um evento ou condição de incerteza que ao ocorrer pode ter efeito positivo ou negativo em relação aos objetivos de um projeto ou empreendimento no tocante a sua execução/implantação/operação. Portanto, pode gerar impactos que vão estar associados as suas causas, cujo planejamento deve antever. As variações nos resultados são esperadas em função das incertezas inerentes à natureza da ação no seu processo de execução, podendo gerar impacto negativo, denominado de risco, ou impacto positivo, sendo assim chamado de oportunidade.

Neste contexto, é preciso apontar os desafios a serem enfrentados, em especial no tocante a antever os impactos e transformações no espaço urbano e metropolitano, a fim de minimizar os impactos negativos e potencializar os impactos positivos. Dentro das atribuições do Estado, que se dá através das políticas públicas, em particular por meio do planejamento e gestão urbana e regional. Em especial, analisar os riscos e ameaças sobre a região, em se mantendo o atual modelo de desenvolvimento econômico, concentrador e desigual, típico de um capitalismo semiperiférico, ou seja, diz respeito a uma posição intermediária na estrutura da economia capitalista mundial no contexto de uma rede de trocas desiguais entre os países centrais, periféricos e semiperiféricos (núcleo central e periferia) (ARRIGHI, 1997).

Cabe então, fazer uma breve retrospectiva do processo histórico de estruturação da região da Baixada Santista, buscando identificar as principais características dos vários períodos de desenvolvimento socioeconômico e os impactos socioespaciais dos grandes empreendimentos instalados na Baixada Santista, em especial na última década com as perspectivas de exploração do pré-sal na Bacia de Santos e outros investimentos ligados à expansão e modernização do Porto de Santos e do Polo Petroquímico de Cubatão. 


\section{BAIXADA SANTISTA NA PERSPECTIVA HISTÓRICA}

A Baixada Santista, histórica região litorânea e portuária do estado de São Paulo, há muito tem importância no cenário político e econômico nacional e internacional por abrigar o maior porto da América Latina, o Porto de Santos, bem como o Polo Industrial Petroquímico de Cubatão. Tais atividades somadas ao Turismo se constituem nas principais bases de sustentação econômica da região, impulsionadas pelo desenvolvimento de diferentes fases do modo de acumulação capitalista que, em média, se sucederam em períodos históricos a cada 50 anos: inicialmente, a economia agroexportadora, com o ciclo do café na virada do século XIX e a estruturação do trinômio ferrovia/porto/cidade; depois a economia industrial-urbana com o processo de industrialização em Cubatão a partir da década de 1950, bem como o desenvolvimento do turismo balneário de massa, que impulsionaram a expansão urbana na região; e agora, no período da acumulação flexível com a reestruturação produtiva do capitalismo, a exploração e produção de petróleo e gás na Bacia de Santos, sob a camada do pré-sal (VIANA, 2010).

Porém, a região, assim como o país, amargou um período de crise econômica nas últimas duas décadas do século XX, fruto dos impactos da globalização econômica e das transformações produtivas do capitalismo, que atingiram fortemente a economia regional, inserida na rede dos fluxos globais. Este processo trouxe grandes mudanças tecnológicas na matriz produtiva e, em conjunto com as privatizações no contexto das políticas neoliberais, provocou significativa retração de postos de trabalho dos principais empregadores da região, o Porto de Santos e a Companhia Siderúrgica Paulista - COSIPA, em Cubatão. Consequentemente, instaura-se um período de crise econômica na região, em que os níveis de desemprego no final da década de 1990 chegaram a mais de $20 \%$ da população economicamente ativa (NESE, 2009).

Todavia, no cenário econômico do país após os anos 2000, Santos e a RMBS vivenciaram uma nova fase de grande "otimismo" quanto às perspectivas futuras da região em função do desenvolvimento das suas principais vocações econômicas, decorrentes das condiçóes geográficas, da biodiversidade dos recursos naturais existentes e da oferta de uma mão de obra barata, fruto da forte migração gerada pelo processo de industrialização do Sudeste. Essa euforia se deu em função da descoberta do pré-sal em 2006, com as perspectivas de implantação da cadeia produtiva de exploração de petróleo e gás na Bacia de Santos, nas áreas do pré-sal no 
estado de São Paulo; a expansão e modernização do Porto de Santos com as Leis dos Portos (1993 e 2013); os vultosos investimentos na modernização e ampliação do Mega Polo Industrial de Cubatão e na Refinaria Presidente Bernardes de Cubatão - RPBC; e o desenvolvimento do potencial turístico da região, principalmente com a emergência das temporadas de cruzeiros marítimos.

Devido às descobertas das reservas de petróleo e gás na Bacia de Santos, o termo 'pré-sal' foi amplamente noticiado pela mídia nacional e regional entre os anos de 2006 e 2012, manifestando um grande otimismo quanto às perspectivas futuras de desenvolvimento do país e da região. Sendo assim, as expectativas futuras de desenvolvimento socioeconômico para a região eram consideradas favoráveis diante do novo cenário.

Vigora o discurso hegemônico do crescimento econômico e do desenvolvimento sustentável ancorados nos avanços da ciência e da tecnologia. Resta então saber até que ponto este discurso camufla os reais problemas socioambientais da região, fruto dos ciclos econômicos de desenvolvimento passados, atrás do velho mito do progresso e da ilusão do desenvolvimento. E se tal "otimismo" se justifica para além da dimensão econômica, em razão das descobertas das reservas de petróleo e gás na Bacia de Santos (Pré-sal), cuja unidade de operação de exploração e produção da Petrobras no Estado de São Paulo (UO-BS) está sediada em Santos, polo central da região.

\section{DA DESCOBERTA A IMPLANTAÇÃO DA CADEIA PRODUTIVA DO PRÉ-SAL}

O Pré-sal é uma área de aproximadamente $800 \mathrm{~km}$ de extensão por $200 \mathrm{~km}$ de largura, que se estende do litoral do Espírito Santo até Santa Catarina e abrange três bacias sedimentares: Espírito Santo, Campos e Santos (Figura 1). As reservas de hidrocarbonetos estão localizadas abaixo da camada de sal em águas profundas, demandando grandes investimentos em pesquisa e tecnologia avançada para descoberta e operação com eficiência em águas ultraprofundas, que estão sendo realizadas pela Petrobras em parceria com fornecedores, universidades e centros de pesquisa.

Segundo a PETROBRAS, isso tem resultado na perfuração de poços no pré-sal em tempo e com custos cada vez menores e com maior segurança. "O custo médio de extração do petróleo do pré-sal vem sendo reduzido gradativamente ao 
longo dos últimos anos. Passou de US\$ 9,1 por barril de óleo equivalente (óleo + gás) em 2014, para US\$ 8,3 em 2015, e atingiu um valor inferior a US 8 por barril no primeiro trimestre de 2016." Como resultado a produção da empresa na camada pré-sal em 2016 bateu "novo recorde mensal em dezembro, atingindo 1,27 milhão de bpd. O volume representa um crescimento de $9 \%$ em relação à produção de novembro de 2016, de 1,16 milhão de bpd. (...)" A produção média da camada de pré-sal subiu 33\% em 2016, para 1,02 milhão de bpd e também foi a maior da história da empresa. Incluindo a produção de 77 milhões de $\mathrm{m}^{3}$ diários de gás natural, a produção média total no país foi de 2,63 milhões de bpd em 2016, uma alta de $1 \%$ em comparação anual. Entre os destaques do avanço da produção, a Petrobras citou o desempenho dos campos de Lula e Sapinhoá, no pré-sal da Bacia de Santos. (VALOR, 2016)

A Bacia de Santos é a maior bacia sedimentar offshore do país, com uma área de $352 \mathrm{mil} \mathrm{km²}$ que está dividida em polos de exploração e produção de óleo e gás, englobando vários campos, dentre eles o Campo de Tupi, hoje denominado Campo Lula (Figura 1). A Petrobras e seus parceiros detêm $40 \mathrm{mil} \mathrm{km}^{2}$ de concessões exploratórias, sendo que $52 \%$ da área ficam em águas paulistas. O restante está situado no Rio de Janeiro (35\%), Santa Catarina (7\%) e Paraná (6\%). Segundo a Petrobras, outra importante conquista alcançada em 2014 foi $100 \%$ de sucesso exploratório no Polo Pré-Sal da Bacia de Santos, ou seja, encontrou-se óleo em todas as perfuraçôes realizadas nessa área (PETROBRAS, 2016).

Para exploração do Pré-sal o governo federal aprovou em 2010 no Congresso Nacional um novo marco regulatório que estabelece as novas regras para exploração e produção de petróleo e gás natural na área do pré-sal e em áreas que venham a ser consideradas estratégicas. Até 2010 vigorou no país o modelo de concessão, no qual a empresa detinha a propriedade sobre o recurso natural e era obrigada a remunerar o governo por isso. Todavia, com a descoberta do pré-sal foram sancionadas as leis 12.276/10 (cessão onerosa e da capitalização da Petrobras), 12.304/10 (criação da empresa pública Pré-sal Petróleo S.A.- PPSA) e 12.351/10 (regime de partilha de produção e do Fundo Social), criando assim um novo marco regulatório. Nos sistemas de cessão onerosa e partilha de produção o Estado tem a propriedade do petróleo produzido. O modelo de concessão continuou valendo nas bacias sedimentares, com exceção do pré-sal e das áreas licitadas após de 2010, em que se aplicavam a nova regra da partilha. (POLIS, 2016). 
Figura 1 Visão dos Polos de Produção do Pré-sal da Bacia de Santos.

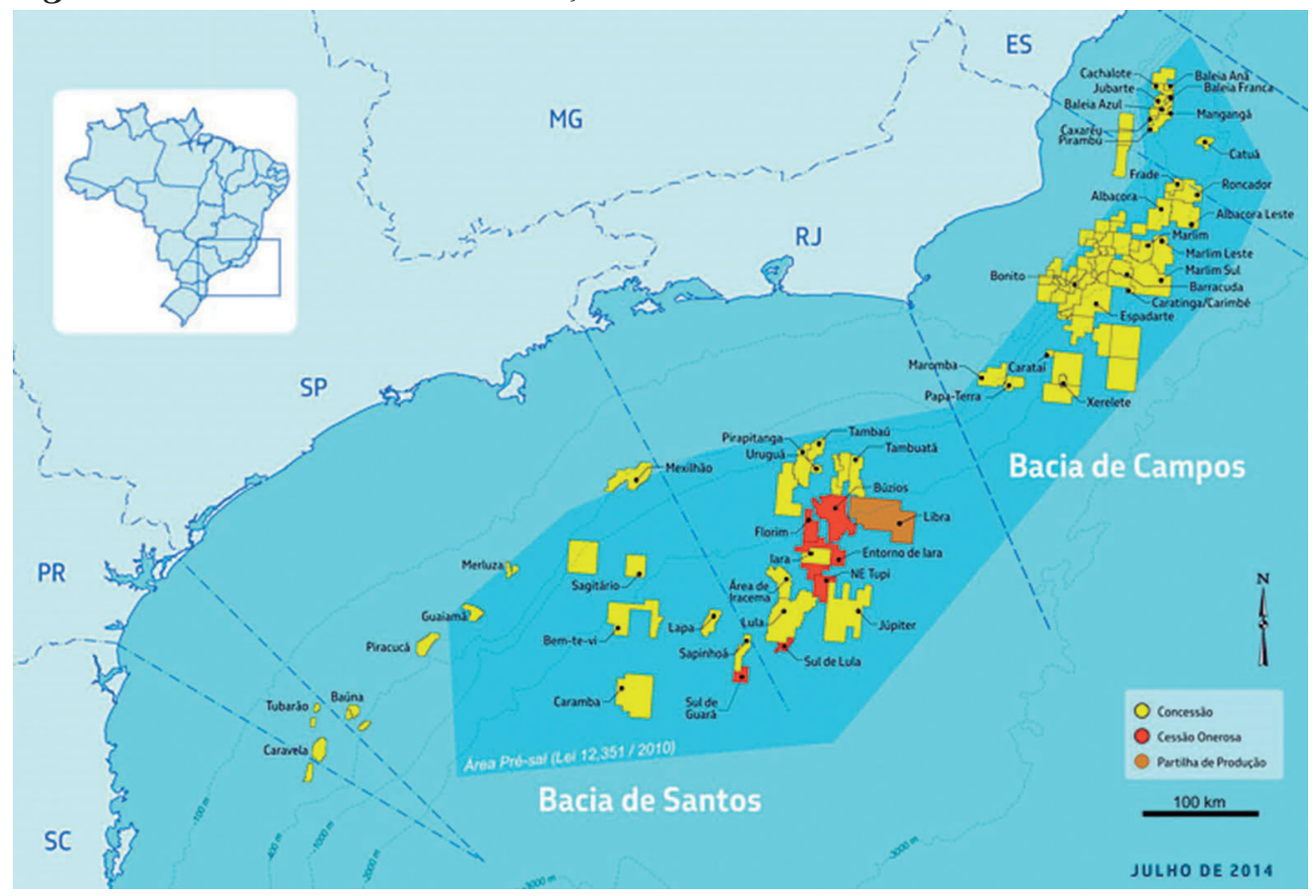

Fonte: Petrobras (julho, 2014).

Pode-se destacar que essa nova perspectiva de desenvolvimento, no período do segundo mandato do governo Lula (2007/2010), representava a possibilidade de autossuficiência econômica do país por meio da exploração dessa matriz energética com as mudanças do novo marco regulatório. Todavia, foi alvo de questionamento em função da queda do preço do barril de petróleo no mercado internacional e da mudança de estratégia de exploração, com a aprovação do Projeto de Lei n. 4.567/16 pela Câmara dos Deputados, que foi sancionada lei pelo presidente da república em 29/11/2016, alterando as regras de exploração dos recursos naturais do pré-sal. O que deve diminuir significativamente os recursos do Fundo Social, a serem destinados para áreas de saúde e principalmente educação, conforme estabelece a Lei Federal n. 12.558/2013, ao se retirar a obrigatoriedade da Petrobras como operadora de todos os campos do pré-sal e repassar tal atribuição a outras empresas que venham assumir essa função.

A Petrobras é uma companhia de energia de capital misto de importância mundial, que apesar dos prejuízos registrados em 2014 e das denúncias e investigações de corrupção, manteve a $28^{a}$ colocação no ranking mundial, segundo publicação da 
revista americana de negócios "Fortune" em 2015. Nas previsões do Plano de Negócios da Petrobras 2009-2013 (2009), o desenvolvimento do pré-sal da Bacia de Santos era considerado uma das mais importantes do país e do mundo. O investimento total em exploração e produção neste período estava previsto em US \$ 104,6 bilhões, sendo 17\% no pré-sal da Bacia de Santos. Isso representava um investimento de cerca de U\$ 18 bilhões até 2013, que poderia chegar a US\$ 99 bilhões até 2020. O atual Plano de Negócios da PETROBRAS 2015-2019, apesar de uma revisão das previsões de investimentos, prevê US \$ 98,4 bilhões de investimentos, priorizando projetos de exploração e produção $(\mathrm{E} \& \mathrm{P})$ de petróleo e gás no país, com ênfase no pré-sal (PETROBRAS, 2016).

Sem dúvida, são cifras que impressionam em termos de investimentos econômicos, porém, uma escala similar de investimentos da Petrobras na Bacia de Campos, que responde por aproximadamente $84 \%$ da produção nacional de petróleo e de $42 \%$ do gás natural, já foi investida na região petrolífera do Norte Fluminense do Rio de Janeiro, com a geração expressiva de empregos diretos e indiretos ligados à indústria do petróleo. No entanto, é uma região marcada pelas desigualdades, o que demonstra que o crescimento econômico por si só não traz prosperidade. "Trata-se de uma região-problema com profundas desigualdades socioespaciais e socioeconômicas, (...); o enclave petrolífero contribuiu para a reprodução do padrão concentrado e polarizado do seu desenvolvimento econômico (...); com isso o mercado de trabalho regional é restrito, seletivo, polarizado e excludente", afirma José Luís Vianna da Cruz (2005, p. 97).

Tal como no Norte Fluminense, a expectativa era de grandes oportunidades de negócios e geração de emprego e renda na Bacia de Santos com as perspectivas de desenvolvimento da cadeia produtiva de exploração de petróleo e gás, cuja Unidade de Operação de Exploração e Produção da Bacia de Santos da Petrobras (UO-BS) está sediada na área central de Santos.

\section{A VALORIZAÇÃO IMOBILIÁRIA: O NOVO "BOOM IMOBILIÁRIO" ESPECULATIVO}

A Petrobras construiu em 2012 a primeira torre dos 03 edifícios previstos no projeto da sua nova sede, em um terreno de $25 \mathrm{mil} \mathrm{m}^{2}$ no bairro do Valongo, que foi adquirido da Prefeitura de Santos, com a previsão de abrigar 6 mil funcionários da empresa. $\mathrm{Na}$ época estimava-se que outros 14 mil prestadores de serviço da 
cadeia produtiva iriam ter como local de trabalho o centro e os bairros adjacentes de Santos, totalizando 20 mil profissionais. O que gerou um processo de valorização imobiliária no bairro do Valongo, com a construção de um edifício corporativo (Wave Office) e de um hotel da rede Ibis, com 480 leitos. O processo de transformação de uso do bairro foi intensificado a partir de 2014 com a inauguração do Museu Pelé, nos antigos Casarôes do Valongo e a construção da primeira torre da Petrobras, sede da Unidade de Operações de Exploração e Produção da Bacia de Santos, que abriga hoje cerca de 2 mil funcionários ${ }^{3}$.

Este processo de valorização e especulação imobiliárias pode ser visualizado em Santos, em especial nos novos empreendimentos que se concentram na orla da praia e no bairro do Valongo, no centro histórico da cidade, levando a uma alta do valor do metro quadrado. "Em regiões valorizadas como essa, o preço do metro quadrado pode chegar a $\mathrm{R} \$ 9.000$, de acordo com imobiliárias locais. Cinco anos atrás, era possível encontrar o metro quadrado a $\mathrm{R} \$ 3.000$ ”, segundo matéria do portal G1 de 14/06/2011 (GLOBO, 2016).

"Desde a descoberta do pré-sal, o preço dos imóveis em Santos e outras cidades da Baixada Santista quase dobrou, segundo o Sindicato da Habitação de São Paulo" (Secovi-SP, 2011). Um estudo divulgado pela entidade aponta que o preço médio do metro quadrado de um imóvel residencial de um dormitório, por exemplo, passou de R \$ 2.602 para R \$ 5.182 de agosto de 2006 a abril de 2011. O consultor do Secovi-SP, Robert Zarif, aponta o pré-sal como o principal motivo do aumento das vendas de imóveis na Baixada Santista”. (Apud SANTOS, 2017). Segundo a Costacurta (2013), com relação à valorização da terra no centro de Santos em especial no bairro Valongo, cinquenta por cento dos quartos do hotel Valongo Brasil (atual Ibis) foram colocados à venda em 2012, antes do início da obra, sendo que no prazo de um mês foram vendidas todas as unidades disponibilizadas. O que mais chama a atenção foi que o preço do metro quadrado dos quartos foi de aproximadamente dezesseis mil reais (apud MARUM, 2017).

Além desse grande investimento com a construção da nova sede, a Petrobras pretende contribuir no projeto de revitalização do antigo bairro, em conjunto

3 Fonte: http://www.santos.sp.gov.br/?q=noticia/891559/bairro-do-valongo-passa-por-momento-especial. Acesso em: 15/04/2016. 
com a Prefeitura de Santos, em especial no tocante à melhoria do sistema viário e de transportes, com a implantação de um ramal de acesso do Veículo Leve sobre Trilhos - VLT. Trata-se do projeto "Porto Valongo Santos", que surgiu em 2007 e que faz parte do "Programa Alegra Centro" da Prefeitura Municipal. (Neste projeto está previsto também a construção de um "mergulhão" para a passagem subterrânea neste trecho, com cerca de $1 \mathrm{~km}$, e um novo terminal turístico de passageiros, dentre outros, mas que até agora não foram implantados). Neste projeto está previsto transformar uma área de 55 mil metros quadrados em um grande complexo turístico, náutico, cultural e empresarial, contando com terminal de cruzeiro, uma marina pública, escritórios, restaurante e terminal de transporte aquaviário, mas que até agora não foram implantados (Litoral Sustentável, 2012).

Tais expectativas e empreendimentos geraram uma onda de valorização imobiliária na região central de Santos. Segundo pesquisas de Marum (2017), a empresa de consultoria e intermediação imobiliária, Lopes em conjunto com as cidades pesquisadas pelo Índice FipeZap, lançou em 2014 uma pesquisa indicando as cidades que tiveram o preço médio do metro quadrado de lançamentos residenciais mais caros do país no ano de 2013. Neste ano, o município de Santos ficou em oitavo lugar, com o preço do $\mathrm{m}^{2}$ avaliado em $\mathrm{R} \$$ 6.080. Outros dois municípios da RMBS entraram na lista, São Vicente em décimo primeiro lugar com o preço do metro quadrado avaliado em R \$ 5.500 e o Guarujá em décimo terceiro lugar com o preço do $\mathrm{m}^{2}$ avaliado em $\mathrm{R} \$ 5.320$. Todavia, em 2014, só o município de Santos aparece na lista e em décimo quarto lugar com o preço do $\mathrm{m}^{2}$ avaliado em $\mathrm{R} \$ 4$ 4.876. Portanto, em apenas um ano o valor do $\mathrm{m}^{2}$ sofreu uma grande queda, em função da atual crise política e econômica vivenciada pelo país.

Esses impactos atingiram não só o bairro Valongo onde foram instalados três empreendimentos ligados a Petrobras, como também no município do Guarujá, onde foi implantada a Saipem, localizada no Complexo Industrial e Naval do próprio município, em Itanhaém, na qual Petrobras se beneficia do aeroporto para transportar os trabalhadores em direção às plataformas em alto mar, e em Cubatão, no qual a Petrobras tem a Refinaria Presidente Bernardes, instalada em 1955, conforme pode-se observar na figura 2. 
Figura 2 Instalações da Petrobras na RMBS (Diagnóstico Participativo Programa de Educação Ambiental PEA-SP. Modificado por SANTOS, A. L. S., 2016).

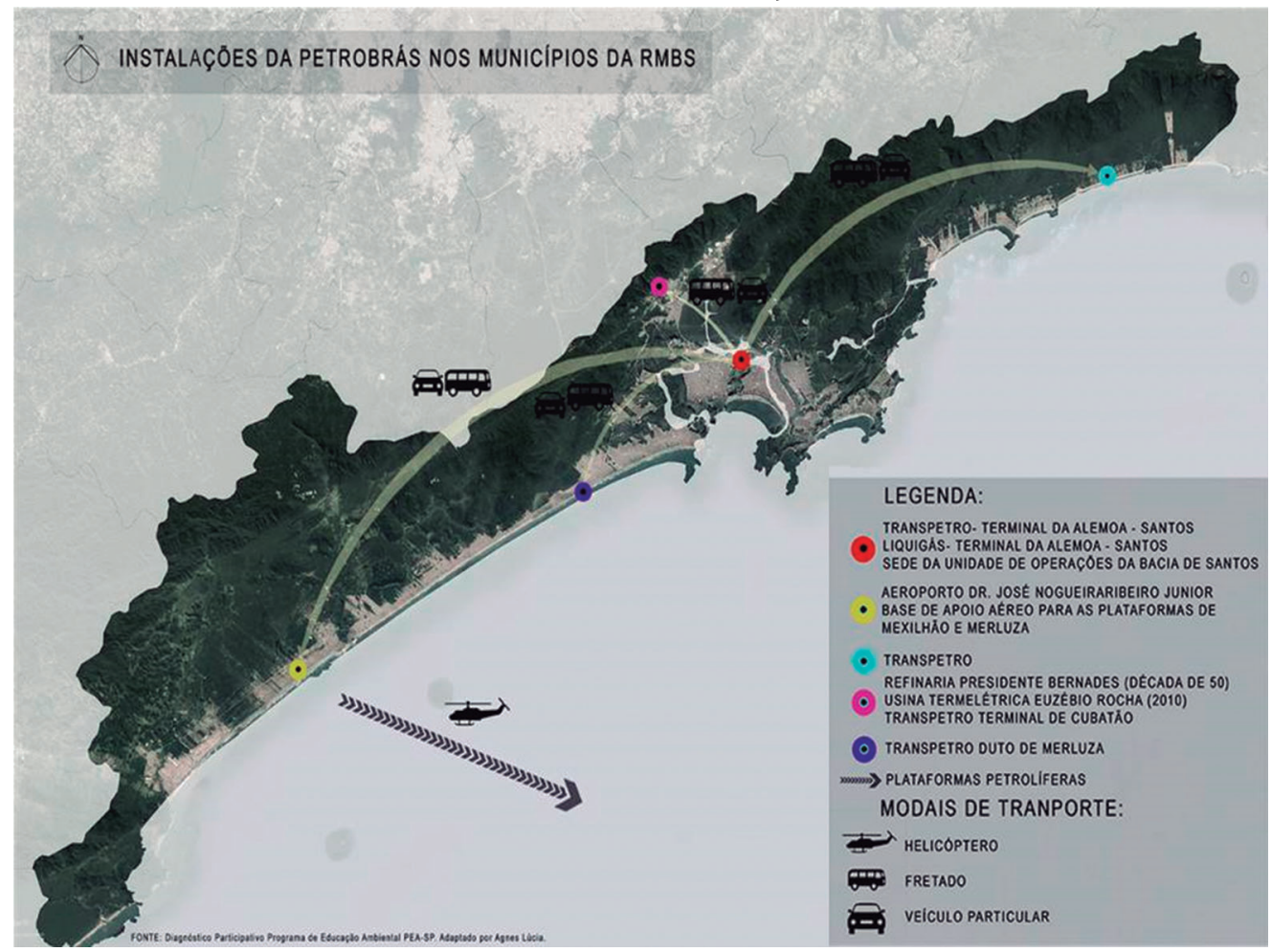

Cabe destacar o Projeto BS-08 do Programa de Mobilização da Indústria Nacional de Petróleo e Gás Natural (PROMIMP), que tem por objetivo dotar a Baixada Santista de recursos de infraestrutura adequada para a construção e manutenção de plantas de processo e de plataformas de petróleo e despertar o interesse do empresariado local para essa nova atividade econômica na região. A título de exemplificação, em 2012 foram destinados para a Baixada Santista 797 vagas por esse programa: “429 para unidades de fornecedores prestadores de serviços à Petrobras em Cubatão e 368 em Santos. As vagas em Cubatão foram destinadas principalmente para trabalhar na prestação de serviços das obras de modernização da Refinaria Presidente Bernardes Cubatão (RPBC), sendo na maioria de nível básico. Em Santos, as vagas oferecidas foram para prestadores de serviços para a Unidade de Operações da Bacia de Santos (UO-BS)” (AGEM, 2016).

Neste contexto de exaltação com relação à exploração e produção de petróleo e gás na Bacia de Santos, esta atividade se torna o principal potencial de desenvolvimento 
econômico futuro da região. Todavia, cabe retratar os riscos inerentes à tal atividade, como os dois grandes acidentes que ocorreram recentemente na região. O primeiro no Terminal Químico Aratú S.A do Grupo Ultracargo na Alemoa, na entrada da cidade de Santos, quando houve um incêndio de amplas proporções e risco que perdurou por vários dias em abril de 2015, para debelar o incêndio em tanques de combustíveis, altamente inflamáveis. Este acidente gerou grande impacto na fauna e flora local, levando a morte de toneladas de peixes no Estuário de Santos e prejudicando a atividade pesqueira. O segundo acidente foi no terminal portuário da Localfrio na margem esquerda do Porto de Santos, no município do Guarujá em janeiro de 2016, que resultou na liberação de gases tóxicos, nocivos à saúde da população, causando desconforto e problemas respiratórios pela fumaça tóxica, que tomou conta do distrito de Vicente de Carvalho e de vários bairros de Santos. O que vem a demonstrar a fragilidade da fiscalização e da gestão de medidas preventivas ao risco nas operações, tanto por parte das empresas, quanto pelos órgãos públicos, que deveriam zelar pela implementação e fiscalização da legislação e normas de licenciamento ambiental estabelecidas. (VIANA, 2015).

\section{INVESTIMENTOS NA MODERNIZAÇÃO DO PORTO DE SANTOS}

Aliava-se a esse "otimismo", a expansão e modernização do complexo portuário no intuito de consolidar o Porto de Santos como concentrador de cargas, denominado hub port, com a previsão de aumento significativo da sua capacidade e da geração de empregos em especial para as grandes obras, mas que deixam de existir com a conclusão das instalações. Por conta disso, a própria consultoria (VKS Partex, 2009) que realizou o estudo na época alertava para o risco do "passivo social" que poderia ser gerado na região com o fim desses trabalhos, ampliando o processo de favelização, um problema que a região já vivenciou no período da industrialização. O Complexo Barnabé-Bagres (Figura 3), idealizado para movimentar 120 milhôes de toneladas por ano, é outro projeto polêmico em termos de impacto ambiental. Trata-se de um novo conjunto de terminais na margem esquerda do cais, na área continental de Santos, que está em processo de estudo de viabilidade. Segundo a Codesp, este é o principal projeto de expansão do setor portuário no país, que deverá agregar ao complexo santista o dobro da sua capacidade de movimentação, o que vai demandar investimentos estimados em $\mathrm{R} \$ 9$ bilhões. (Diário do Litoral, 2013)

A construção das Avenidas Perimetrais nas duas margens do porto, prevista desde os anos 1950 no Plano de Prestes Maia, já é uma realidade na margem de 
Santos e no lado do Guarujá, realizadas com recursos do Programa de Aceleração do Crescimento - PAC do governo federal. A dragagem de aprofundamento do canal para 15 metros, após muitos impasses no processo de licenciamento ambiental foi realizada, possibilitando a circulação de navios de maior porte, contando com recursos do PAC. O Plano de Expansão do Porto de Santos que previa a expansão da área portuária com a construção de novos terminais como da Empresa Brasileira de Terminais Portuários - Embraport, que hoje tem a capacidade de movimentar 1,2 milhão de TEUS (Twenty-foot Equivalent Unit) e o da Brasil Terminal Portuário - BTP, construído na área do antigo Lixão da Alemoa e que pertence à Europe Terminals da armadora MSC Shipping, deu início às suas operações em 2013 com a capacidade de movimentação de 2,5 milhões de TEUS e capacidade projetada de movimentação de 2,0 milhões de toneladas de granéis líquidos (Figura 3).

Figura 3 Planta de localização dos principais terminais do Porto de Santos.

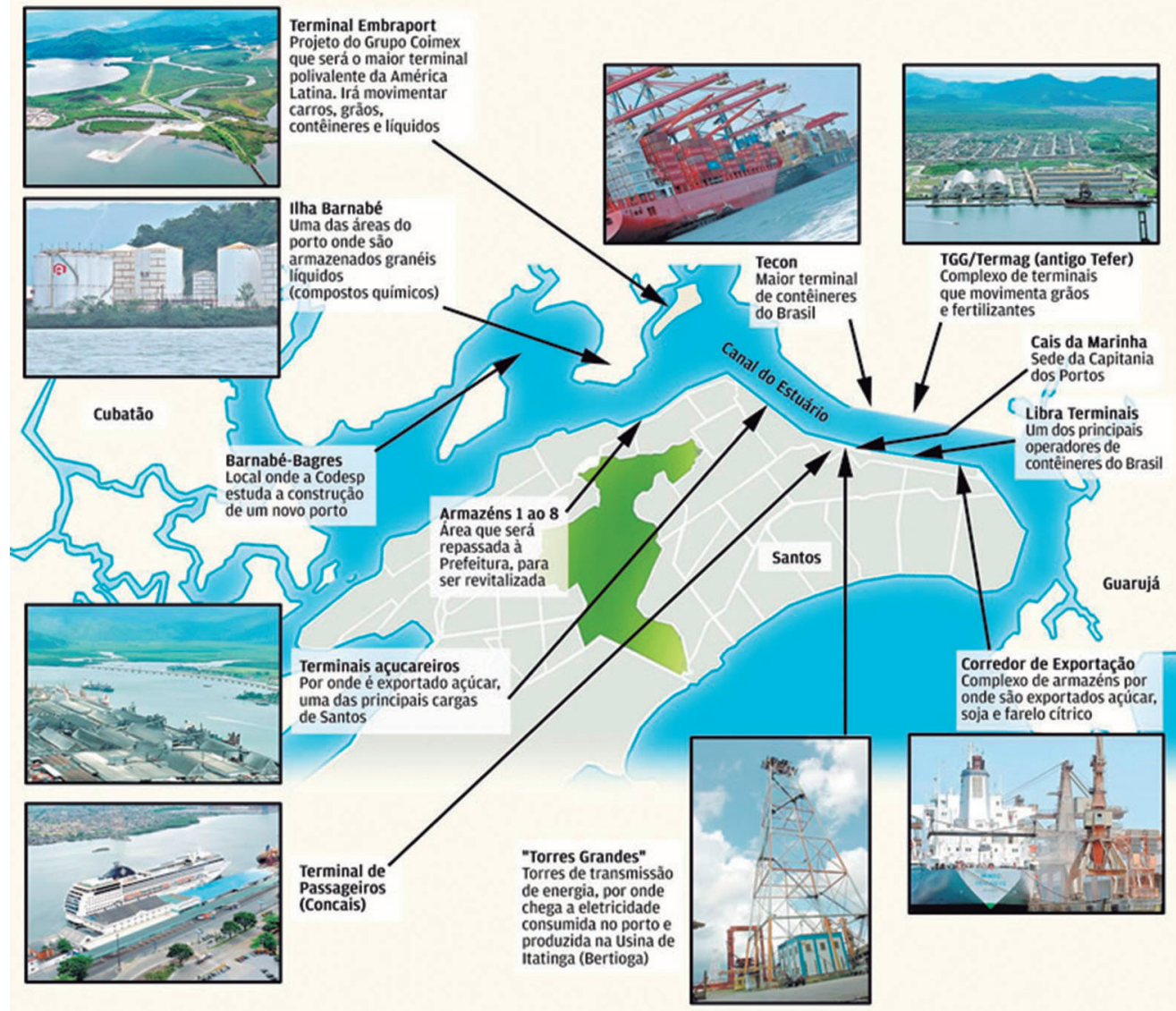

Fonte: site www.santosexport. com. Acesso em: 20/01/2010. 
Somados à otimização e expansão de outros terminais existentes como Santos-Brasil, Libra Terminais, Tecondi e na área do bairro do Saboó. Esse aumento da movimentação e da implantação de novos terminais demanda investimentos permanentes em dragagem e na melhoria da acessibilidade ao porto e região, em complementação ao sistema rodoviário existente, por meio da multimodalidade dos transportes (ferroviário, hidroviário, aeroviário e dutoviário).

\section{A MODERNIZAÇÃO E AMPLIAÇÃO DO POLO INDUSTRIAL DE CUBATÃO}

Além disso, na última década foram feitos investimentos bilionários na modernização e ampliação do Polo Industrial de Cubatão, sobretudo na Usiminas (antiga, COSIPA) e na Refinaria Presidente Bernardes de Cubatão - RPBC. Estes foram anunciados durante o evento Mega Polo 2008 realizado em Cubatão em maio de 2008, investimentos de US \$ 6,6 bilhões para a expansão e modernização das atuais unidades industriais e na construção de novos empreendimentos no Polo Industrial de Cubatão até 2012. Na época, já estavam sendo aplicados US\$ 2,6 bilhões desse montante em obras na USIMINAS, na RPBC, na Carbocloro e na Petroque. Apesar de o governo federal ter liberado expressivos recursos da União para convênios do Programa de Aceleração do Crescimento (R \$ 550 milhões), com o Governo do Estado para saneamento ( $\mathrm{R} \$ 286$ milhões) e prefeituras para habitação ( $\mathrm{R}$ \$ 265 milhões), esses investimentos podem contribuir para minimizar o passivo socioambiental da região, mas não necessariamente atender a demanda futura.

Além dos acidentes já citados, cabe destacar o grande impacto social e econômico na RMBS em função da desativação da Usiminas de Cubatão (antiga Cosipa) com a paralisação de fornos em 2015 e a parada da Usina em 2016, como medida de ajuste a crise econômica. O que resultou na demissão gradativa de 4 mil funcionários de sua usina siderúrgica localizada no município de Cubatão (SP), afetando a economia da região e tende a trazer forte impacto com a previsão de retração de 30 mil empregos diretos e indiretos, segundo o Sindicato dos Siderúrgicos e Metalúrgicos da Baixada Santista (A Tribuna, 2016). Uma situação semelhante ao processo de privatização da Cosipa na década de 1990, que gerou uma significativa retração dos postos de trabalho, através das demissões e dos programas de desligamentos incentivados (PDI), agravando a crise econômica na região, com a ampliação das desigualdades e dos impactos socioambientais no território 
regional. Convém destacar também que no ano de 2015, a empresa italiana Saipem, instalada no Guarujá, apresentou um plano de reestruturação para se recuperar de prejuízo acumulado de $€ 920$ milhões no primeiro semestre do ano. E uma das medidas, as quais não foram detalhadas, é a redução das atividades no Brasil e no Canadá, que geraram uma baixa contábil de $€ 211$ milhões no balanço da empresa. A companhia também anunciou a demissão de 8,8 mil funcionários como parte do plano de economizar $€$ 1,3 bilhão até o final do ano de 2017 (BRASIL ENERGIA, 2016).

\section{DIVERSIFICAÇÃO DO TURISMO}

Outro fator é o desenvolvimento do potencial turístico da região, principalmente através da diversificação do turismo, como o turismo de negócios e a melhor exploração das temporadas de cruzeiros marítimos, buscando ampliar o tempo de permanência do turista na região. $\mathrm{O}$ turismo voltado às temporadas dos transatlânticos tem movimentado um volume significativo de recursos, passageiros e navios no terminal do Terminal Marítimo de Passageiros Giusfredo Santini do Porto de Santos - Concais (2016). Na temporada de 2006/2007 movimentou 491.873 passageiros e 15 navios, chegando a mais que dobrar na temporada de 2010/2011, atingindo a cifra de 1.120 .830 passageiros e 22 navios, quando então passou a ter uma redução gradativa, movimentando na temporada de 2015/2016 cerca de 760 mil passageiros e 10 navios (Globo, 2016). Todavia, na última temporada (2016/2017) a previsão é de uma queda de $42 \%$ do número de passageiros, com a previsão de 409.796 passageiros no embarque e desembarque no cais santista e apenas 7 navios.

\section{PERSPECTIVAS FUTURAS: OPORTUNIDADES E RISCOS}

Dentro do quadro apresentado, pode-se observar que as expectativas futuras para a região até 2012 eram "as melhores possíveis" diante das projeções para a economia do país na época. A projeção era que a Baixada Santista deveria acompanhar a dinâmica da economia nacional, acarretando um grande crescimento econômico e populacional ${ }^{4}$ em decorrência desses vultosos investimentos públicos e

4 "Mais 456 mil virão em 20 anos. Nos próximos 20 anos, a população da Baixada Santista crescerá 456 mil pessoas, mais do que o número atual de habitantes de Santos. Antes disso, a Cidade perderá o antigo posto de maior da região, em termos demográficos: será ultrapassada por Praia Grande e Guarujá, onde viverão 40\% dos 2 milhões 246 mil moradores locais calculados para 2030", segundo dados da Superintendência Regional Sabesp. (A Tribuna, 17/05/2009, p. A-6) 
privados na região. Vislumbrava-se a tendência do aquecimento da economia regional e a expansão da oferta de oportunidades e empregos, em especial os de maior qualificação profissional, voltados à Bacia de Santos, e na construção civil com as inúmeras obras em andamento e as previstas.

Esse conjunto de informações divulgado nos meios de comunicação até alguns anos atrás pode demonstrar as expectativas ufanistas em relação ao futuro da Baixada Santista diante dessa nova fase de acumulação do capital, na qual a Baixada Santista ganhou destaque como uma região estratégica para o desenvolvimento econômico do estado e do país.

Trata-se, portanto, de uma grande oportunidade que pode promover desenvolvimento desde que explorada de forma adequada, mas que ao vigorar o modelo de desenvolvimento atual pode agravar problemas já existentes, criar novos e ampliar as desigualdades. A exploração de petróleo caracteriza-se como uma atividade altamente impactante (risco) que demanda que a região se prepare com antecedência para receber tais impactos. Em especial os impactos negativos, conforme preocupação de várias lideranças regionais, com o crescimento populacional pelo fluxo migratório, a sobrecarga da infraestrutura, a deficiência na qualificação da mão de obra local e a falta de um debate regional mais amplo. O que pode ampliar as desigualdades e comprometer a qualidade ambiental da região, do mesmo modo como aconteceu no município de Macaé, importante região petrolífera do Norte do Rio de Janeiro.

Há, portanto, um paradoxo entre esse otimismo exacerbado e a tensão em relação aos riscos e ameaças gerados pelo progresso técnico, motor do desenvolvimento econômico. Portanto, é preciso reconhecer e enfrentar a problemática atual da RMBS, uma herança dos ciclos de desenvolvimento econômico anteriores, fruto de um processo de industrialização a baixos salários e de um modelo de desenvolvimento urbanístico excludente e concentrador que vigora nas nossas cidades. E, ainda, expressão da histórica desigualdade existente no país e na estrutura da sociedade brasileira.

Ao mesmo tempo em que a mídia noticiava essa euforia em relação às perspectivas futuras de desenvolvimento para o Brasil e a região, veiculava-se, não com o mesmo destaque na época, matérias que retratavam os problemas da região, que também são comuns às demais metrópoles brasileiras, tais como: crescimento urbano desordenado; número significativo de habitaçôes precárias em áreas impróprias e/ou irregulares em contraponto à valorização imobiliária das áreas centrais, 
ampliando a segregação socioespacial dos mais pobres e o crescimento da verticalização na faixa da orla da praia.

Segundo Rovena Negreiros da Fundação Seade, em oficina temática realizada pela AGEM BS em maio/2017, o "tamanho da exclusão social” na RMBS resulta na ocupação irregular de 423 mil pessoas em assentamentos precários, cerca de $20 \%$ do total de domicílios (déficit habitacional). São 371 áreas de risco mapeadas, com cerca de 10 mil domicílios, o que representa quase $2 \%$ do total de domicílios da região. No tocante a questão da vulnerabilidade social com base na renda, com base em dados de 2010, com exceção de Santos, nenhum outro município da Baixada Santista tem renda per capita maior que um salário mínimo atual. A pesquisadora ainda ressalta que o alto índice de mortalidade infantil na regiāo $(14,5$ mortes/mil, um dos maiores do estado) também impacta no ritmo de envelhecimento da população, que por sua vez, gera impactos em outras áreas: "na habitação, por exemplo, o tipo de moradia a ser planejado deverá levar em conta os idosos e um número menor de moradores em cada residência (média de 3, segundo dados da Seade)". Quanto a pirâmide etária da região, a pesquisadora aponta para o envelhecimento da população, dizendo "há um recuo no número de pessoas em idade ativa, entrantes no mercado de trabalho também diminuíram. Em contrapartida, há o crescimento da população idosa, principalmente, mulheres. O índice de envelhecimento está relacionado à quantidade de pessoas com mais de 60 anos, comparando com a faixa das pessoas com mais de 20 anos: em média, entre 15 e $20 \%$ da população serão idosos. Em Santos, serão mais de 20\%” (AGEM. 2016).

Desta forma, muitos problemas referenciados permanecem na pauta regional, como as deficiências na infraestrutura urbana, principalmente na coleta e tratamento do esgoto, na destinação dos resíduos sólidos e gargalos no sistema viário metropolitano que causam problemas no trânsito e congestionamentos, bem como a falta de integração dos transportes metropolitanos; a degradação ambiental dos ecossistemas com a poluição das praias e corpos d'água e também questôes ligadas à saúde pública, ao desemprego, a violência urbana, dentre outros.

Ampliam-se assim, cada vez mais às desigualdades sociais e econômicas, o que se reflete no espaço urbano-regional pela crescente segregação territorial dos mais pobres e a grande heterogeneidade na qualidade da infraestrutura urbana dos municípios. A dualidade na região se dá entre os municípios e dentro das cidades, na forma de ocupação do espaço urbano entre a porção legal e a outra parte da cidade, que fica esquecida na sua carência e irregularidade. 
A questão central que se coloca é até que ponto essas perspectivas promissoras de desenvolvimento, enaltecidas na mídia local e pelas lideranças políticas e empresariais, poderiam realmente trazer ganhos para a região como um todo, com a justa distribuição da riqueza gerada e a destinação de recursos para o enfrentamento do passivo socioambiental existente e para melhorar a infraestrutura regional. Será que a Baixada Santista está preparada para receber tantos impactos gerados por essa gama de empreendimentos e projetos que estão na pauta nacional, estadual e regional?

Cabe então, fazer uma breve análise sobre os desafios colocados ao planejamento urbano e regional no contexto do atual sistema de gestão metropolitana da RMBS e sua interface entre os demais entes federativos.

\section{DESAFIOS DO PLANEJAMENTO URBANO-REGIONAL: OS (DES) COMPASSOS DO SISTEMA DE PLANEJAMENTO E GESTÃO METROPOLITANOS FRENTE ÀS PERSPECTIVAS FUTURAS}

As regiões metropolitanas são a mais complexa e evoluída forma de organização urbana alcançada pela humanidade. Sua importância e variedade de suas consequências [sic] justificam o interesse que despertam entre os estudiosos; a procura dos meios para o seu controle representa o mais amplo desafio aos planejadores (...). (REIS FILHO, 1996, p. 15)

O Brasil é uma república federativa, o que pressupõe uma organização de poder compartilhado entre os três entes federativos (União, Estados e Municípios) por meio de um pacto federativo instituído pela Constituição Federal. Uma federação deve conjugar a autonomia dos entes federativos e garantir a interdependência. Portanto, caracteriza-se como um processo político de controle mútuo, através de uma coordenação intergovernamental, o que sempre foi um problema na história da federação brasileira. A grande discussão do pacto federativo é a questão da descentralização, em especial num país continental como o Brasil, que apresenta grandes diferenças regionais, culturais e socioeconômicas, com alto grau de urbanização. (ABRUCIO, 2001; p. 16)

No processo de redemocratização do Brasil acirra-se a crise do estado nacional desenvolvimentista e a crise fiscal, quando o governo federal perde poder para os estados e municípios. A Constituição Federal de 1988 dá mais poderes ao município, fortalecendo o chamado municipalismo autárquico como espaço de resolução dos problemas, através das políticas públicas. Porém, contraditoriamente, a maioria dos municípios brasileiros é de pequeno porte e depende das receitas federais e/ou 
estaduais para exercer suas funções. Outra mudança é que a criação das regiōes metropolitanas passa a ser uma atribuição dos Estados, que no caso brasileiro não se caracterizam como entes federativos, ou seja, não se constituem como um poder metropolitano.

Com o acelerado processo de metropolização, várias regiōes metropolitanas foram criadas pelos Estados, que tendem a priorizar as suas realidades e demandas específicas com a criação de critérios próprios na institucionalização das regiões metropolitanas. Porém, apesar da aprovação recente do Estatuto da Metrópole (lei federal n. 13.089/2015) ainda faltam critérios funcionais para identificar a diversidade e complexidade da rede urbana das metrópoles brasileiras, mecanismos para garantir a descentralização e a cooperação intergovernamental, através de recursos estáveis (orçamento metropolitano), incentivo à cooperação entre os municípios (articulação regional) e a participação dos governos superiores, estadual e federal.

A região metropolitana da Baixada Santista (RMBS) foi instituída pelo Governo do Estado de São Paulo em 1996. Para enfrentar os desafios regionais frente à problemática atual e às perspectivas futuras, a RMBS conta com uma estrutura de planejamento e gestão metropolitanos composta pela Agência Metropolitana da Baixada Santista (AGEM), uma autarquia com vínculo estadual, braço executivo do Conselho de Desenvolvimento da Região Metropolitana da Baixada Santista CONDESB, criado pela Lei Complementar n 815/96. Este conselho é paritário e tem função normativa e deliberativa, sendo composto apenas por representantes do governo do estado e das 09 prefeituras dos municípios que integram a região. Além disso, existe o Fundo de Desenvolvimento Metropolitano da Baixada Santista como suporte financeiro e as Câmaras Temáticas para assessoria ao CONDESB. Apesar da AGEM ter o mérito de ter constituído uma base cartográfica regional e elaborado vários estudos técnicos e planos regionais sobre questôes de interesse comum, como transportes e sistema viário metropolitano, turismo, habitação, dentre outros, pode-se verificar um olhar fragmentado sobre a região. Na prática, pouco se efetivou dos planos e projetos regionais elaborados, com resultados concretos ainda incipientes em relação à demanda regional.

Em 2013 foi lançado o Plano Metropolitano de Desenvolvimento Estratégico da Baixada Santista (PMDE-BS), desenvolvido pela Agência Metropolitana da Baixada Santista (AGEM) em parceria com uma consultoria especializada que estabelece um planejamento integrado para a RMBS até 2030, em quatro áreas estratégicas: Habitação, Mobilidade, Saneamento e Desenvolvimento Econômico. 
No tocante ao eixo Petróleo e Gás as expectativas são de grande crescimento no horizonte da análise desse plano, principalmente após a definição do marco legal e exploração das reservas situadas no pré-sal já leiloadas, com a previsão de geração de 36 mil empregos diretos e indiretos.

O aumento da participação da RMBS neste setor o destaca como o maior responsável pelo volume de investimentos previstos para a regiāo, com mais de R \$ 114 bilhões até o ano de 2030, o equivalente a quase $70 \%$ de todo o investimento estimado para as cidades da Baixada Santista no mesmo período. (PMDE-BS, 2013, p. 101).

Todavia, a RMBS não tem autonomia orçamentária e política nas decisões de interesse regional, que dependem do orçamento e iniciativas do Governo do Estado. Além disso, a atual estrutura do sistema de planejamento e gestão metropolitanos não contempla a participação da sociedade civil organizada e dos legislativos municipais e de órgãos federais que atuam na região. Há uma desigualdade entre os municípios que acaba privilegiando os investimentos no município sede, em detrimento dos municípios de menor porte e importância econômica, gerando disputas e a fragmentação dos interesses. Existem vários planos e recortes de planejamento da região da Baixada Santista que precisam ser compatibilizados e integrados entre si, em função dos diversos planos regionais (PMDE-BS, ZEE-BS, Plano do CBH-BS, PDZ do Porto de Santos) com os planos diretores e as leis de uso e ocupação do solo dos 9 municípios.

Esse conjunto de instrumentos de desenvolvimento urbano-regional e de gestão ambiental incide sobre o mesmo território geográfico, o que é um fator positivo, e demonstra que não faltam na RMBS planos, projetos e leis de regulação urbana e ambiental, ou seja, planejamento. $\mathrm{Na}$ verdade, falta autonomia política e financeira às instituições regionais, e, principalmente pactuação e cooperação entre os três entes federativos e a efetiva participação da sociedade civil nos debates e decisões regionais. Portanto, questiona-se a eficácia desses vários instrumentos de planejamento e gestão que refletem a disputa de poder no controle do uso e ocupação do espaço urbano-regional, o que ocorre em especial, entre os três níveis de governos que, norteados por diferentes escalas de abrangência, especificidades setoriais e distintos interesses políticos e econômicos, geram situações de conflito e tensão, tendo em vista que são entes autônomos e nem sempre aceitam a coordenação intergovernamental. Numa federação isso se torna mais complicado por duas razões: a primeira é que, ao contrário de um estado unitário, é uma coordenação entre entes autônomos, eles podem não querer a coordenação. (ABRUCIO, 2001) 
Grosso modo, pode-se dizer que na RMBS, ao governo federal cabe a gestão do Porto de Santos, o maior da América Latina e a principal atividade de sustentação da região, através da Secretaria Especial dos Portos - SEP e da CODESP; e também a gestão da RPBC e da cadeia de exploração e produção do Petróleo e Gás, através da Petrobras, bem como das unidades de conservação ambiental de âmbito federal, como o Estuário Santista, através do IBAMA. Ao governo estadual cabe disciplinar também a Política de Meio Ambiente e Saneamento Ambiental, através da fiscalização e dos licenciamentos ambientais, bem como dos investimentos em infraestrutura de saneamento, por meio da Secretaria do Meio Ambiente - SMA, CETESB e SABESB. Além da Política de Transportes e Sistema Viário Metropolitanos, de fundamental importância para o desenvolvimento das atividades econômicas de sustentação regional e as Políticas de Saúde, Educação e Segurança Pública. Dada a grande ingerência das outras esferas de poder, aos municípios parece restar a regulação de uso e ocupação do solo, através das políticas de desenvolvimento urbano e da legislação urbanística, que em grande parte atende aos interesses do mercado imobiliário e dos setores da construção civil, que em geral contam com anuência das administrações municipais, como, por exemplo, a verticalização excessiva dos prédios nas zonas da orla marítima nos municípios centrais em especial, Santos, com a construção de verdadeiras torres que estão mudando a paisagem urbana e causam impactos urbanos e ambientais, tais como: trânsito, sobrecarga da infraestrutura urbana, problemas de insolação e ventilação, dentre outros. Por outro lado, essa valorização imobiliária leva à expulsão da população de menor renda para áreas cada vez mais periféricas, ampliando a segregação socioespacial, caracterizando, assim, um modelo urbanístico anárquico e inadequado as especificidades de uma zona costeira, que reflete no território as desigualdades da estrutura social brasileira.

Neste contexto, vislumbra-se um sistema de planejamento e uma gestão metropolitana que busque compatibilizar esses vários planos, projetos e eixos indutores de desenvolvimento a partir de uma visão de totalidade da região, através de uma agenda regional participativa que integre o conjunto da sociedade civil. Assim, deve-se estabelecer um diálogo entre os vários setores públicos e privados no intuito de promover o desenvolvimento regional de forma sustentável, por meio da governança pública, o que pressupõe pactuação, corresponsabilidade e participação.

Há um esforço da AGEM BS neste sentido de adequar o Plano Metropolitano de Desenvolvimento Estratégico (PMDE) concluído em 2014 no ao Plano de Desenvolvimento Urbano Integrado (PDUI), exigência do Estatuto da Metrópole, 
que deve ser aprovado por lei estadual até janeiro de 2018. Desde 2015 estão sendo realizados debates pela AGEM BS neste sentido sobre as adequações da RMBS ao novo marco legal, sendo realizadas recentemente oficinas temáticas com especialistas nos principais eixos de interesse comum para dar subsídio ao projeto de lei que deverá ser encaminhado à Assembleia Legislativa até o segundo semestre de 2017.

Trata-se, portanto, de um grande desafio que não se resolve apenas no plano técnico, mas, sobretudo, no plano político e cultural. O que requer uma mudança da cultura técnica e política ainda vigente no país, norteada pela centralização, pelo patrimonialismo e imediatismo político, pela descontinuidade das políticas públicas e pelo clientelismo como forma de cooptação das lideranças e grupos sociais. Ao persistir num modelo de desenvolvimento perverso, pautado na modernização excludente, na concentração de renda e no fortalecimento do capital, que privilegia a dimensão econômica em detrimento das políticas socioambientais é preciso refletir se há alternativas para promover um desenvolvimento pautado nas premissas da sustentabilidade, no contexto de um capitalismo selvagem que cada vez mais se recicla através de recorrentes "crises econômicas" para ampliar a acumulação, gerando assim mais desigualdade.

\section{CONSIDERAÇÕES FINAIS}

A ideia [sic] de desenvolvimento está no centro da visão do mundo que prevalece em nossa época. Nela se funda o processo de invenção cultural que permite ver o homem como um agente transformador do mundo. Dá-se como evidente que este interage com o meio no empenho de efetivar suas potencialidades. (FURTADO, 2002, p. 7)

Pode-se concluir que há uma nítida dualidade entre otimismo e insegurança no futuro em relação às perspectivas de desenvolvimento para a RMBS, em função do expressivo volume de investimentos previstos para desenvolvimento das múltiplas vocações econômicas da região (portuária, industrial, turística e agora petrolífera), principalmente com as expectativas da implantação da cadeia de exploração e produção de petróleo e gás na Bacia de Santos, no chamado pré-sal. Apesar do otimismo que vigorou nos últimos anos. Tal dubiedade entre otimismo e insegurança em relação ao modelo de desenvolvimento norteado pelo progresso das inovações tecnológicas e pelo viés econômico leva ao questionamento do histórico modelo perverso de distribuição de renda adotado no país. Este gerou um acelerado crescimento econômico e urbano no período desenvolvimentista, chamado de anos gloriosos, mas de forma desigual e concentrada, que se reflete até hoje em grandes heterogeneidades regionais e sociais. 
A superação dos problemas crônicos e estruturais do país e da região passa pelo enfrentamento dos mesmos e da priorização dos investimentos em um conjunto de políticas públicas consistentes, de forma integrada e complementar, para galgar o estágio de desenvolvimento desejado, em bases sustentáveis. Isso requer seriedade na gestão pública, criatividade e investimentos consistentes nas políticas sociais, em especial nas áreas de educação, saúde, habitação e assistência social para combater as grandes mazelas do modelo de desenvolvimento e urbanização adotado no país, que se reflete no território das nossas cidades. O que passa pela sustentabilidade urbana, a partir de um conjunto de açóes e prioridades que busque a superação da pobreza, a promover a equidade e a justiça social, maior equilíbrio ambiental, procurando minimizar as externalidades negativas sobre o território e para as gerações futuras. (BORELLI, 2014).

O que vai depender também da forma como as potencialidades da região vão ser exploradas e da utilização das riquezas geradas para resolver os problemas regionais e os impactos gerados pelos grandes empreendimentos. Pressupõe também, o enfrentamento da problemática regional com a diminuição das desigualdades e melhor distribuição das riquezas geradas, com respeito ao meio ambiente, ou seja, a construção de um modelo de desenvolvimento regional sustentável. Em geral, o que se vislumbra é um desenvolvimento com qualidade de vida que promova a melhor distribuição de renda e a diminuição das desigualdades sociais e urbanas, em consonância com a proteção do meio ambiente, através de um planejamento regional com visão de totalidade e participação democrática.

Trata-se, portanto, de um grande desafio para a RMBS que demanda novos arranjos de gestão institucional na busca de uma regionalização democrática através do reforço do federalismo cooperativo, da participação social e da governança regional, que possibilite o fortalecimento político e econômico da região frente aos demais poderes constituídos e às ingerências externas. Isso requer um novo modelo político-administrativo, que possibilite a descentralização dos recursos e das decisões, buscando reverter tendência centralizadora, autoritária e tecnocrática que marcou nossa história no século XX. Para sair do antigo paradigma é essencial modernizar as máquinas públicas para reconstrução do Estado em prol de uma gestão mais democrática e efetiva. Outro desafio à regionalização se refere à necessidade de cooperação entre os entes municipais, por meio de consórcios ou similares. Estas relações intermunicipais constituem algo ainda embrionário no país e sofrem resistência tanto dos políticos locais como dos ocupantes dos cargos estaduais. 
Uma regionalização democrática implica na maior articulação entre os vários agentes sociais, econômicos e políticos da região na resolução das questôes de interesse comum para proposição conjunta de uma agenda regional. Envolve também investimento em um maior conhecimento da região através da pesquisa e de um processo contínuo de planejamento regional integrado e com visão de totalidade, no intuito de antever os impactos e nortear os investimentos necessários ao almejado "desenvolvimento regional integrado e sustentável" da Baixada Santista. Tal desafio vai depender da forma como as potencialidades da região vão ser exploradas e da priorização das riquezas geradas para a resolução dos problemas e melhoria da infraestrutura, possibilitando assim, a superação da desordem e do atraso, fruto de um desenvolvimento capitalista semiperiférico, desigual e combinado, pautado no progresso linear e na concentração de renda. Desta forma, a ação do Estado, através do planejamento e gestão urbano e metropolitano é de fundamental importância no enfrentamento dos obstáculos e na "concertação" dos vários agentes regionais frente às perspectivas futuras.

Portanto, parece ainda vigorar uma visão romântica da realidade, expressão de uma crença no velho desenvolvimento sem enxergar além do convencional para poder superá-lo, ou seja, buscar fora do pensamento hegemônico uma nova forma de organização social. A utopia por sua vez é o discurso do possível e do impossível, extraído da fruição, da superação do olhar convencional, do chamado campo cego, assim como nos ensina Henry Lefebvre (2008).

\section{REFER̂̂NCIAS}

\section{Livros}

ABRUCIO, F. L. e SOARES, M. M. (2001). Redes Federativas no Brasil: cooperação intermunicipal no Grande ABC. São Paulo, Fundação Konrad Adenauer, Série Pesquisas n. 24.

ARRIGHI, G. (1997). A ilusão do desenvolvimento. Petrópolis/RJ, Vozes.

BRANDÃO, M.V. M.; MORELL, M. G. G.; SANTOS, A. R. (2015). Baixada Santista: transformações na ordem urbana. Observatório das Metrópoles. São Paulo: Letra Capital.

CRUZ, J. L. V.; ARAÚJO, T. B; SCHIREIBER, W. M.; VIANA, M. A. et al. (2005). Brasil, o desafio da diversidade: experiências de desenvolvimento regional. Rio de Janeiro, SENAC Nacional.

DIEGUES, A. C. (2000). O Mito Moderno da Natureza Intocada. São Paulo, Hucitec.

DUPAS, G. (2006). O mito do progresso ou progresso como ideologia. São Paulo, UNESP. 
FURTADO, Celso. (2009). Desenvolvimento e Subdesenvolvimento. Rio de Janeiro, Contraponto e Centro Internacional Celso Furtado.

. (2002). Em Busca de Novo Modelo: reflexões sobre a crise contemporânea. São Paulo, Paz e Terra.

GONÇALVES, A. e RODRIGUES, M. A. G. (2016). Direito do petróleo e gás: marco regulatório, aspectos ambientais e internacionais. Santos: Editora Universitária Leopoldianum.

GONÇALVES, A. e NUNES, L. A. P. (2008). O Grande Porto: a modernização no porto de Santos. Santos/SP: Realejo Ediçōes.

LEFEBVRE, H. (2008). A Revolução Urbana. Tradução Sérgio Martins, Belo Horizonte, UFMG.

. (2001). O Direito à Cidade. São Paulo, Centauro, 2001.

OLIVEIRA, F. de. (2003). Crítica à razão dualista. O Ornitorrinco. São Paulo, Boitempo.

RATTNER, H. (2005) O Resgate da Utopia: cultura, política e sociedade. São Paulo: Palas Athena.

SACHS, I. (1993). Estratégias de transição para o século XXI - Desenvolvimento e meio ambiente, São Paulo, Studio Nobel e Fundap.

SILVA, G. \& COCCO, G. (1999). Cidade e portos: os espaços da globalização. Rio de Janeiro: DP\&A.

SOUZA, M. L. (2005). O Desafio Metropolitano. Um estudo sobre a problemática sócioespacial nas metrópoles brasileiras. Rio de Janeiro, Bertrand Brasil.

\section{Capítulos de Livros}

VEIGA, J. E. (1993). A Insustentável Utopia do Desenvolvimento. In LAVINA, L.; CARLEIAL, L. M.; NABUCO, M. R. (Org.). Reestruturação do espaço urbano e regional no Brasil. São Paulo: Hucitec e ANPUR.

VIANA, M. A. (2011). "Valorização do Espaço Urbano na Relação Cidade/Porto: as intervenções urbanísticas em Santos e regiāo.” VAZQUEZ, D. A. (org.), In: A Questão Urbana na Baixada Santista: políticas, vulnerabilidades e desafios para o desenvolvimento. Santos: Universitária Leopoldianum, UNISANTOS, p. 179 a 206.

. (2005). "A articulação regional no Grande ABC”. Cruz, J. L. (org.) In: Brasil, o Desafio da Diversidade: experiências de desenvolvimento regional. Rio de Janeiro, Senac.

VIANA, M. A.; e SILVA, I. (2016). Impactos da verticalização em Santos: um olhar sobre o bairro da ponta da praia. In: SALVI, A. E.; PEREZ C. B. (Org.). Arquitetura: Ambiente e Sustentabilidade. Santos: Editora Universitária Leopoldianum, p. 69-97.

\section{Artigos de periódicos}

BORELLI, Elizabeth. Do porto ao pré-sal: sustentabilidade urbana na Baixada Santista. Revista de Direito da Cidade, v. 6, n. 2. ISSN 2317-7721 p. 583-605. 
DIEGUES, A. C. (1992). Desenvolvimento Sustentável ou Sociedades Sustentáveis: da crítica dos modelos aos novos paradigmas. In São Paulo Perspectiva, Revista da Fundação Seade, v. 6, n. 1 e 2, São Paulo e a Eco 92, jan./jul. 1992; p. 22-29.

REIS FILHO, N. G. (1996). Notas sobre a organização das Regiōes Metropolitanas. Série Urbanismo. Cadernos de Pesquisa do LAP n. 12. Faculdade de Arquitetura e Urbanismo, São Paulo: USP, mar.-abr.1996.

ROBINSON, J. et al. (1990). Defining a sustainable society. Values, principles and definitions. In: Alternatives: perspectives on society, technology and environment. v. 17:2.

VIANA, M. A. (2016). Sustentabilidade e Desenvolvimento urbano-regional: Baixada Santista em perspectiva, desafios para um desenvolvimento sustentável. XIV Ciclo de Debates em Economia Industrial, Trabalho e Tecnologia, SP: PUC SP, Anais.

\section{Teses, dissertações e monografias}

MARUM, V. O. (2017). Avaliação dos impactos urbanos e socioambientais gerados pela implantação e perspectivas futuras da cadeia produtiva de petróleo e gás em Santos, relatório parcial de pesquisa de iniciação científica, sob orientação Profa. Dra. Mônica A. Viana, Santos/SP: UniSantos, fevereiro de 2017.

SANTOS, A. L. S. (2017). Levantamento e sistematização de dados e informações sobre os impactos urbanos e socioambientais da cadeia produtiva de petróleo e gás em Santos, SP. Relatório parcial de pesquisa de iniciação científica, sob orientação Profa. Dra. Mônica A. Viana, Santos/SP: UniSantos, fevereiro de 2017.

VIANA, M. A. (2010). Navegando pelas ondas do Desenvolvimento: Baixada Santista em busca de um porto seguro. Desenvolvimento, Metropolização e os (des) compassos da gestão urbano-regional em múltiplos olhares sociais. Tese de doutorado, Programa de Pós-graduação em Ciências Sociais da PUC SP.

\section{Textos extraídos da internet}

JUNIOR, C. (2010). Nova descoberta do pré-sal pode dobrar reservas de petróleo no Brasil. Folha de São Paulo, 29 de outubro de 2010. Disponível em: http://www1.folha.uol.com.br/ mercado/822358-nova-descoberta-do-pre-sal-pode-dobrar-reservas-de-petroleo-no-brasil. shtml. Acesso em: 20/02/2015.

GOVERNO DO ESTADO DE SÃO PAULO. (2013). Plano Metropolitano de Desenvolvimento Estratégico da Baixada Santista - PMDE. AGEM-BS e Geobrasilis. Disponível em: http://www.agem.sp.gov.br/pmdebs/. Acesso em: 20 fev. 2016.

NESE - Núcleo de Pesquisas e Estudos Socioeconômicos da Universidade Santa Cecília. (2009). Balanço do Emprego Formal na Baixada Santista. Relatório Estatístico. Santos/ SP: UNISANTA/PMS, 2009. Disponível em: http://www.nese.unisanta.br/download/ caged/2009-12.pdf. Acesso em: 15/01/2010. 
POLIS, I. (2016). O marco legal do petróleo e gás no Brasil: reflexões sobre as possibilidades de implementação de políticas públicas. Observatório Litoral Sustentável, Instituto Polis, São Paulo. Disponível em: http://litoralsustentavel.org.br/camaras-tematicas/mesa-dedialogo/noticias-ct-mesa-de-dialogo/consulta-publica-observatorio-dos-royalties. Acesso em: 20 fev. 2016.

POLIS, I. (2016). Os Royalties e os Municípios do Litoral Norte e Baixada Santista. Consulta pública para elaboração da proposta do Observatório dos Royalties. Observatório Litoral Sustentável, Instituto Polis, São Paulo. Disponível em: http://litoralsustentavel. org.br/outras-publicacoes/os-royalties-e-os-municipios-do-litoral-norte-e-baixadasantista/Acesso em: 20 fev. 2016.

RIBEIRO, L. C. de Q., SANTOS Jr, O. A. e RODRIGES, J. M. (2015). Estatuto da Metrópole: avanços, limites e desafios. Disponível em: http://www.observatoriodasmetropoles. net/index.php?option=com_k2\&view=item \&id=1148\%3Aestatuto-da-metr\%C3\%B3poleavan\%C3\%A7os-limites-e-desafios\&Itemid=180\&lang=pt. Acesso em: 25 jan. 2016.

SECOVI (2011). "Descoberta do pré-sal dobra valor de imóveis na Baixada Santista". Disponível em: http://memoria.ebc.com.br/agenciabrasil/noticia/2011-06-14/descobertado-pre-sal-dobra-valor-de-imoveis-na-baixada-santista. Acesso em: 18 dez. 2016. 
